\title{
Inducible nitric oxide synthase and tumor necrosis factor- $\alpha$ in delayed gastric emptying and gastrointestinal transit induced by lipopolysaccharide in mice
}

T. Inada, N. Hamano, M. Yamada, A. Shirane and K. Shingu
Department of Anesthesiology, Kansai Medical University,

Osaka, Japan
Correspondence

T. Inada

Department of Anesthesiology

Kansai Medical University

10-15 Fumizono-cho, Moriguchi

Osaka 570-8507

Japan

Fax: +81-6-6991-1301

E-mail: takefumi@wd5.so-net.ne.jp

....................

Received October 27, 2005 Accepted July 27, 2006

\begin{abstract}
Gastrointestinal motility disturbances during endotoxemia are probably caused by lipopolysaccharide (LPS)-induced factors: candidates include nitric oxide (NO), tumor necrosis factor- $\alpha$ (TNF- $\alpha$ ), interleukin- $1 \beta$, and interleukin-6. Flow cytometry was used to determine the effects of LPS and these factors on gastric emptying (evaluated indirectly by determining percent gastric retention; \%GR) and gastrointestinal transit (GIT) in male BALB/c mice (23-28 g). NO (300 $\mu \mathrm{g} /$ mouse, $\mathrm{N}=8)$ and TNF- $\alpha(2 \mu \mathrm{g} /$ mouse, $\mathrm{N}=7)$ increased $(\mathrm{P}<0.01)$ GR and delayed GIT, mimicking the effect of LPS (50 $\mu \mathrm{g} / \mathrm{mouse})$. During early endotoxemia ( $1.5 \mathrm{~h}$ after LPS), inhibition of inducible NO synthase (iNOS) by a selective inhibitor, $1400 \mathrm{~W}(150 \mu \mathrm{g} / \mathrm{mouse}$, $\mathrm{N}=11)$, but not antibody neutralization of TNF- $\alpha(200 \mu \mathrm{g} / \mathrm{mouse}, \mathrm{N}$ $=11)$, reversed the increase of GR (\%GR $78.8 \pm 3.3$ vs $47.2 \pm 7.5 \%)$ and the delay of GIT (geometric center $3.7 \pm 0.4 v s 5.6 \pm 0.2$ ). During late endotoxemia ( $8 \mathrm{~h}$ after LPS), both iNOS inhibition $(\mathrm{N}=9)$ and TNF- $\alpha$ neutralization $(\mathrm{N}=9)$ reversed the increase of GR (\%GR 33.7 \pm 2.0 vs $19.1 \pm 2.6 \%(1400 \mathrm{~W}$ ) and $20.1 \pm 2.0 \%$ (anti-TNF- $\alpha$ )), but only TNF- $\alpha$ neutralization reversed the delay of GIT (geometric center $3.9 \pm 0.4 v s 5.9 \pm 0.2$ ). These findings suggest that iNOS, but not TNF- $\alpha$, is associated with delayed gastric emptying and GIT during early endotoxemia and that during late endotoxemia, both factors are associated with delayed gastric emptying, but only TNF- $\alpha$ is associated with delayed GIT.
\end{abstract}

\section{Introduction}

Endotoxemia, which occurs after lipopolysaccharide (LPS) injection, delays gastric emptying and disrupts intestinal transit (1-7). However, it is not clear whether the latter effect involves a delay or acceleration since both have been reported (1,5-7). While uncertainties remain about the nature of the effect of LPS on gastrointestinal motility, the effect is
Key words

- Endotoxin

- Inducible nitric oxide

synthase

- Tumor necrosis factor- $\alpha$

- Gastric emptying

- Gastrointestinal transit

- Lipopolysaccharide 
bances of gastrointestinal motility, but it is not known which of them causes the disturbance during endotoxemia.

Since there is some controversy about the effect of LPS on intestinal transit, the first aim of this study was to determine the effect of LPS on gastric emptying and gastrointestinal transit in mice using a new method, the flow cytometric method, that is exquisitely sensitive to the effects of drugs on gastrointestinal motility $(9,10)$. The method has advantages over other standard methods such as those using radioactive chromium or phenol red as markers in that it does not use an isotope and can measure the center of gravity of the marker (a measure of the distribution of the marker within the gastrointestinal tract) as well as how far the marker progresses along the intestine, thus greatly increasing the accuracy of measurement of gastrointestinal transit. The second aim was to determine whether NO, TNF- $\alpha$, IL-1 1 , or IL-6 have an endotoxemia-like effect on gastric emptying and gastrointestinal transit in normal mice. Third, we sought to further investigate any such endotoxemialike effect by determining whether inhibition of NO, TNF- $\alpha$, IL-1 $1 \beta$, or IL-6 reversed the disturbances during endotoxemia.

\section{Material and Methods}

Mice

Male BALB/c mice (Charles River, Yokohama, Japan), aged 6-7 weeks and weighing 23-28 g, were used. The study was approved by the Institutional Committee on Animal Research. The mice were housed under standardized environmental conditions, with a 12-h light/dark cycle. The animals were fasted for 16-24 h but were allowed free access to water until 20-30 min before having a test liquid introduced into the stomach. Each animal was housed individually in a wire-mesh cage to prevent coprophagy during fasting. All experiments measuring gastrointestinal motility were started between 6:00 and 9:00 am.

\section{Measurement of gastrointestinal function}

We evaluated gastric emptying and gastrointestinal transit by infusing liquid containing fluorescent and nonfluorescent microbeads into the stomach and measuring the quantity of the fluorescent microbeads at a fixed time thereafter using a flow cytometer $(9,10)$. A mixture of fluorescent polystyrene microbeads $6 \mu \mathrm{m}$ in diameter (Flow Check High Intensity Alignment Grade Particles, Polysciences, Inc., Warrington, PA, USA), and nonfluorescent microbeads $2.14 \mu \mathrm{m}$ in diameter (Sphero UV fluorescent particles, BD Biosciences, San Jose, CA, USA) was used. The manufacturers provided these microbeads in water: $1 \mu \mathrm{L}$ contained $2 \times 10^{3} 6-\mu \mathrm{m}$ microbeads or $6 \times 10^{6}$ 2.14- $\mu \mathrm{m}$ microbeads.

Each mouse was lightly anesthetized with halothane and $0.2 \mathrm{~mL}$ saline containing the 50 $\mu \mathrm{L}$ fluorescent and $2 \mu \mathrm{L}$ nonfluorescent microbeads was infused via a metal cannula (PS 7912, ISIS Co., Ltd., Osaka, Japan) into the stomach $(9,10)$. An excess of smaller 2.14$\mu \mathrm{m}$ nonfluorescent microbeads was included to block the absorption of the fluorescent markers by the gastrointestinal mucosa $(9,10)$.

Thirty minutes later, the mouse was killed by an overdose of halothane. This time interval was selected to obtain the geometric center of 6-7 and to prevent the leading edge of the test fluid from going beyond the ileocecal junction $(9,10)$. The esophagus, just proximal to the gastric fundus, and the duodenum, just distal to the pylorus, were crossclamped, and the stomach and small intestinal tract were removed. If there was chyme in the stomach or small intestinal tract, the data were not used. The intestinal tract was placed on a ruled template and divided into ten equal segments. The stomach and each segment of the intestine were placed in individual tubes containing $5 \mathrm{~mL}$ phosphatebuffered saline. Each tube was vortexed 
and $600 \mu \mathrm{L}$ of the supernatant was filtered through a strainer (Cell-Strainer; BD Biosciences).

The quantity of fluorescent microbeads in each sample was measured using a flow cytometer (FACScan; BD Biosciences). The fluorescent microbeads are labeled with a fluorescent yellow-green dye, which absorbs the light of a 488-nm argon laser and emits yellow-green fluorescence. During flow cytometry, the fluorescent microbeads were gated by their distinct forward and side lightscatter profiles. The gated particles were further analyzed for the presence of intense fluorescence. The number of particles with high intensity fluorescence was counted for $30 \mathrm{~s}$ at a "high flow rate" $(9,10)$ (Figure 1). Gastric emptying of the liquids was indirectly evaluated by determining the percent of gastric retention (\%GR) (11) as described below:

$\% \mathrm{GR}=($ stomach count/total count $) \times 100$,

where total count $=$ stomach $\operatorname{count}+\Sigma($ count in each intestinal segment).

Gastrointestinal transit was assessed us-
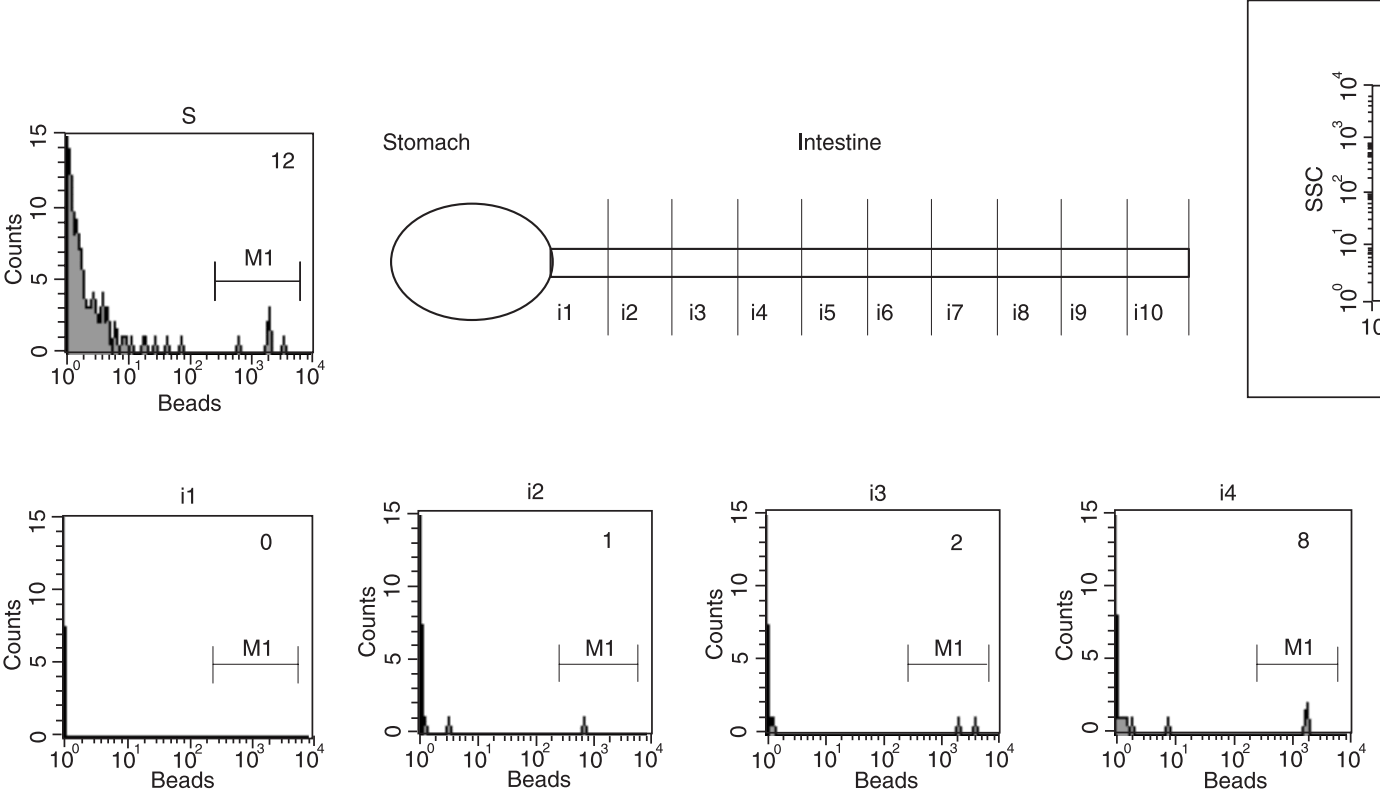

S
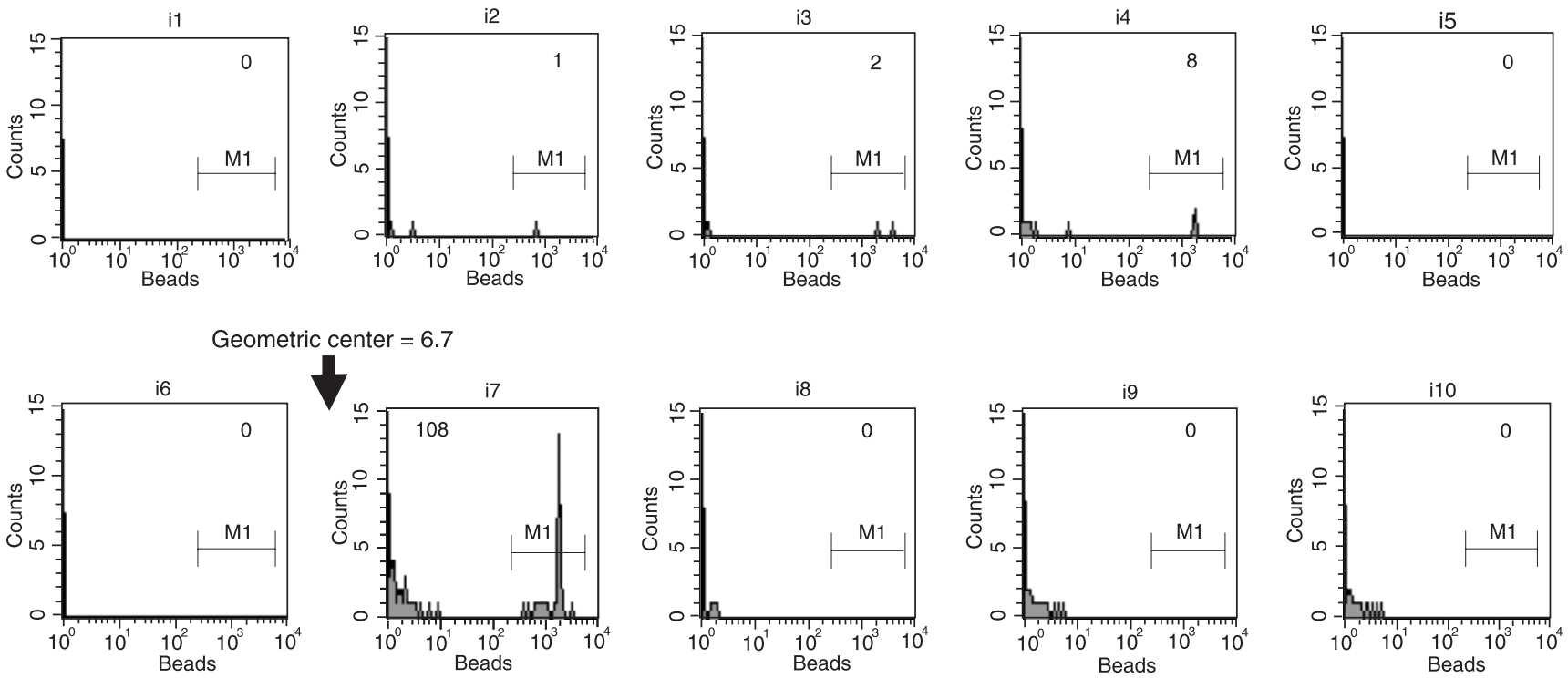

Figure 1. Measurement of gastric emptying and gastrointestinal transit by flow cytometry. This was done by infusing liquid containing fluorescent microbeads into the stomach and measuring the quantity of the beads at $30 \mathrm{~min}$ thereafter. The stomach and ten-equally divided segments of the small intestine were placed in individual tubes containing phosphate-buffered saline. The tubes were vigorously vortexed and the number of beads in the supernatant was counted using flow cytometry. In flow cytometry, the fluorescent microbeads were gated by their distinct forward (FSC) and side (SSC) light-scatter profiles (inset scatter plot). The gated (R1) particles were further analyzed for the presence of intense fluorescence, and the number of the particles with high intensity fluorescence (M1) was counted. Numbers in histograms indicate the amount of beads within each segment. S, stomach; i1-i10, small intestinal segments. 
ing the "geometric center" (GC; the center of gravity). This was calculated by a method described previously $(9,10)$ : $\mathrm{GC}=\Sigma$ (count in intestinal segment $\mathrm{x}$ intestinal segment number) $/ \Sigma$ (count in each intestinal segment).

\section{Effect of lipopolysaccharide}

Since a previous study indicated that the cytokine profiles, especially those of TNF- $\alpha$ and $\mathrm{NO}$, and the resulting disturbances in gastrointestinal transit were different at early $(1.5 \mathrm{~h})$ and late $(8 \mathrm{~h})$ times after bolus ip injection of LPS (5), we measured gastric retention and gastrointestinal transit at both times. Mice were randomly allocated to receive an ip injection of saline $(250 \mu \mathrm{L})$ or LPS (10 or $50 \mu \mathrm{g}$ in $250 \mu \mathrm{L}$ saline; Escherichia coli O111:B4, Sigma, St. Louis, MO, USA). We selected the LPS doses based on our aim to study the toxin's effect at well below the lethal dose in mice. We determined the maximum sublethal dose of the lot of LPS used (lot No. 50K4088) to be 100 $\mu \mathrm{g}$ for male BALB/c mice. To further determine the efficacy of LPS, we also measured the serum TNF- $\alpha$ levels at $1.5 \mathrm{~h}$ after LPS (when the levels are considered to be highest) and tissue inducible NOS (iNOS) and neuronal NOS (nNOS) protein expressions at $8 \mathrm{~h}$ after LPS (when iNOS expression is considered to be high), as described below.

\section{Enzyme-linked immunosorbent assay}

Serum was separated by blood centrifugation $\left(4^{\circ} \mathrm{C}, 20,000 \mathrm{~g}\right.$, for $\left.5 \mathrm{~min}\right)$ and stored at $-80^{\circ} \mathrm{C}$ until measurement. Concentrations of TNF- $\alpha$ were measured by enzyme-liked immunosorbent assay (Biosource International, Camarillo, CA, USA) according to manufacturer instructions. All samples were measured in triplicate. The inter- and intraassay coefficients of variation of the kit were $\leq 8.7$ and $\leq 6.5 \%$, respectively, and the detection limit was $3 \mathrm{pg} / \mathrm{mL}$.

\section{Western blotting}

Mid jejunum was frozen in liquid nitrogen, homogenized, and lysed with ice-cold lysis buffer (50 mM Tris-HCl, pH 8.0, 0.1\% SDS, $1 \%$ NP-40, 5 mM EDTA, $150 \mathrm{mM} \mathrm{NaCl}, 2$ $\mathrm{mM}$ DTT, $1 \mathrm{mM}$ sodium orthovanadate; Sigma), and a protease inhibitor cocktail (Roche Applied Science, Mannheim, Germany). The lysates (20 $\mu$ g per lane) were then separated on a 7.5\% SDS-polyacrylamide gel and transferred to a PVDF membrane (SequiBlot PVDF Membrane; Bio-Rad Laboratories, Hercules, CA, USA). iNOS and nNOS were detected with anti-iNOS antibody (1:2500; Pharmingen, San Diego, CA, USA) and nNOS antibody (1:1000; Zymed Laboratories Inc., San Francisco, CA, USA), respectively, and actin was detected with anti-actin antibody (1:2000; C-11; Santa Cruz Biotechnology, Inc., Santa Cruz, CA, USA). These proteins were then visualized using anti-IgGHRP of appropriate species (Zymed Laboratories) and ECL plus Western blotting detection reagent (Amersham Biosciences, Buckinghamshire, UK).

\section{Effects of cytokines}

Mice were randomly allocated to receive $250 \mu \mathrm{L}$ saline ip, $2 \mu \mathrm{g}$ recombinant murine TNF- $\alpha$, IL-1 1 , or IL-6 (endotoxin level $<1$ $\mathrm{EU} / \mu \mathrm{g}$ ) (PeproTech EC Ltd., London, UK) in $250 \mu \mathrm{L}$ saline $i p$, or $300 \mu \mathrm{g}$ of 1-hydroxy-2oxo-3,3-bis (2-aminoethyl)-1-triazene (NOC18; an NO donor; Dojindo Molecular Technologies, Inc., Kumamoto, Japan) (12) subcutaneously (sc) in $100 \mu \mathrm{L}$ saline. Gastric retention and gastrointestinal transit were measured 30 min after ip saline or cytokine injection, or $1 \mathrm{~h}$ after sc NOC18 injection. The doses, routes, and time intervals were selected on the basis of previous studies (12-15), and a preliminary study indicated that these doses were likely to affect gastric emptying, thus precluding insufficient dosing. We limited the time to $30 \mathrm{~min}$ in order to measure the injected 
cytokine (or NO) effect and minimize the effects of other cytokines induced in vivo by injected cytokines (or NO).

\section{Effects of inhibitors}

To determine the effect of inhibitors of iNOS and TNF- $\alpha$ on gastric emptying and gastrointestinal transit in early and late endotoxemia, mice were given ip saline, $150 \mu \mathrm{g}$ of the selective iNOS inhibitor N-(3-(aminomethyl) benzyl) acetamidine ( $1400 \mathrm{~W}$; Alexis Biochemicals, Lausen, Switzerland), or 200 $\mu \mathrm{g}$ anti-mouse TNF- $\alpha$ antibody. The antimouse TNF- $\alpha$ polyclonal antibody was purified, had a low endotoxin content $(<2.91 \mathrm{EU} /$ $\mathrm{mg}$ ), and was preservative- and carrier-free (Pierce Endogen Inc., Woburn, MA, USA). Each inhibitor was administered ip in a volume of $250 \mu \mathrm{L}$ saline $1 \mathrm{~h}$ before measurement. The doses of the inhibitors used were based on previous studies $(6,16)$ and our preliminary experiments showing that any further increase in the dose failed to further affect the gastric emptying/intestinal transit. Since a previous study (6) and our preliminary results indicated that $\mathrm{N}^{\omega}$-nitro-L-arginine methyl ester (a nonselective inhibitor) and 1-(2-trifluoromethylphenyl) imidazole (a selective nNOS inhibitor) both delay gastric emptying in normal mice, we chose to use a selective iNOS inhibitor.

\section{Statistical analysis}

Data are reported as means \pm SEM. Oneway analysis of variance with Bonferroni correction was used to compare data between groups, with the level of significance set at $\mathrm{P}<0.05$.

\section{Results}

\section{Efficacy of LPS treatment}

At $1.5 \mathrm{~h}$ after LPS administration, serum concentrations of TNF- $\alpha$ increased signifi-

cantly $(495.8 \pm 47.7 \mathrm{pg} / \mathrm{mL}$ with LPS $v s$ below the detection limit with saline, $\mathrm{N}=3$ for each group). At $8 \mathrm{~h}$ after LPS, iNOS was expressed in the intestine, whereas nNOS expression became undetectable (Figure 2). These findings are consistent with previous reports showing that iNOS expression is induced and nNOS expression is down-regulated by LPS treatment $(17,18)$, demonstrating the efficacy of endotoxemia induction in our study.

\section{Effect of lipopolysaccharide}

LPS increased gastric retention and delayed gastrointestinal transit during both early $(1.5 \mathrm{~h})$ and late $(8 \mathrm{~h})$ endotoxemia $(\mathrm{P}<0.05$; Figure 3A). The transit histogram shows that, with increasing LPS, the marker distribution at both times became broader and the distinct peak of distribution became less evident (Figure 3B).

\section{Effects of cytokines}

$\mathrm{NO}$ and all the cytokines tested increased gastric retention $(\mathrm{P}<0.05$; Figure 4$)$. Gastrointestinal transit was delayed only by NO and TNF- $\alpha(\mathrm{P}<0.01$; Figure 4). Therefore, the effect of NO and TNF- $\alpha$ mimicked that observed during endotoxemia.

\section{Effects of inhibitors}

At $1.5 \mathrm{~h}$ after LPS administration, inhibition of iNOS with $1400 \mathrm{~W}$ reversed the increase in gastric retention and the delay in

Saline

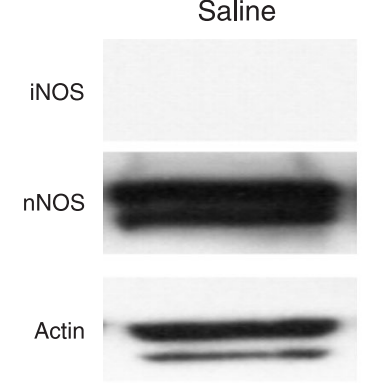

LPS

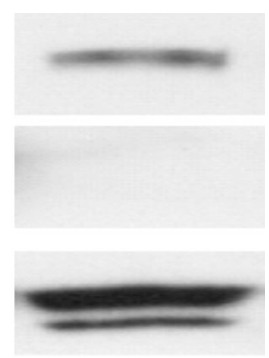

Figure 2. Expression of inducible nitric oxide synthase (iNOS) and neuronal nitric oxide synthase (nNOS) in jejunum at $8 \mathrm{~h}$ after ip lipopolysaccharide (LPS) $(50 \mu \mathrm{g})$ or saline. Representative data of five independent experiments. 
gastrointestinal transit $(\mathrm{P}<0.01)$, while TNF$\alpha$ neutralization with anti-TNF- $\alpha$ antibody had no significant effect (Figure 4). At $8 \mathrm{~h}$ after LPS administration, both iNOS inhibition and TNF- $\alpha$ neutralization reversed the increase in gastric retention $(\mathrm{P}<0.01)$, while only TNF- $\alpha$ neutralization was able to reverse the delay in gastrointestinal transit $(\mathrm{P}$
$<0.01$ ) (Figure 5). In otherwise untreated mice, $1400 \mathrm{~W}$ had no significant effect on gastric retention or gastrointestinal transit (\%GR: $12.2 \pm 2.1$ with saline $v s 14.8 \pm 2.3 \%$ with $1400 \mathrm{~W}, \mathrm{GC}: 6.9 \pm 0.3$ with saline $v s$ $6.8 \pm 0.4$ with $1400 \mathrm{~W}, \mathrm{~N}=5$ for each group, $\mathrm{P}>0.05)$. Anti-TNF- $\alpha$ antibody also had no significant effect on gastric retention or gas-

A
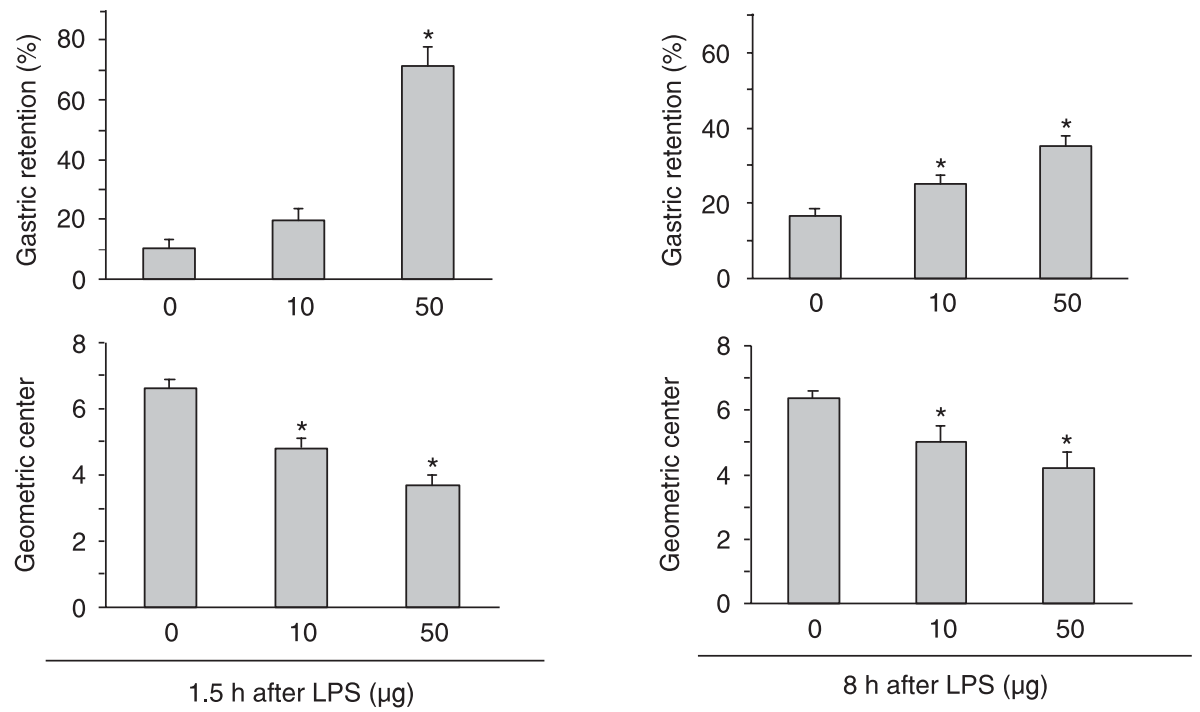

B
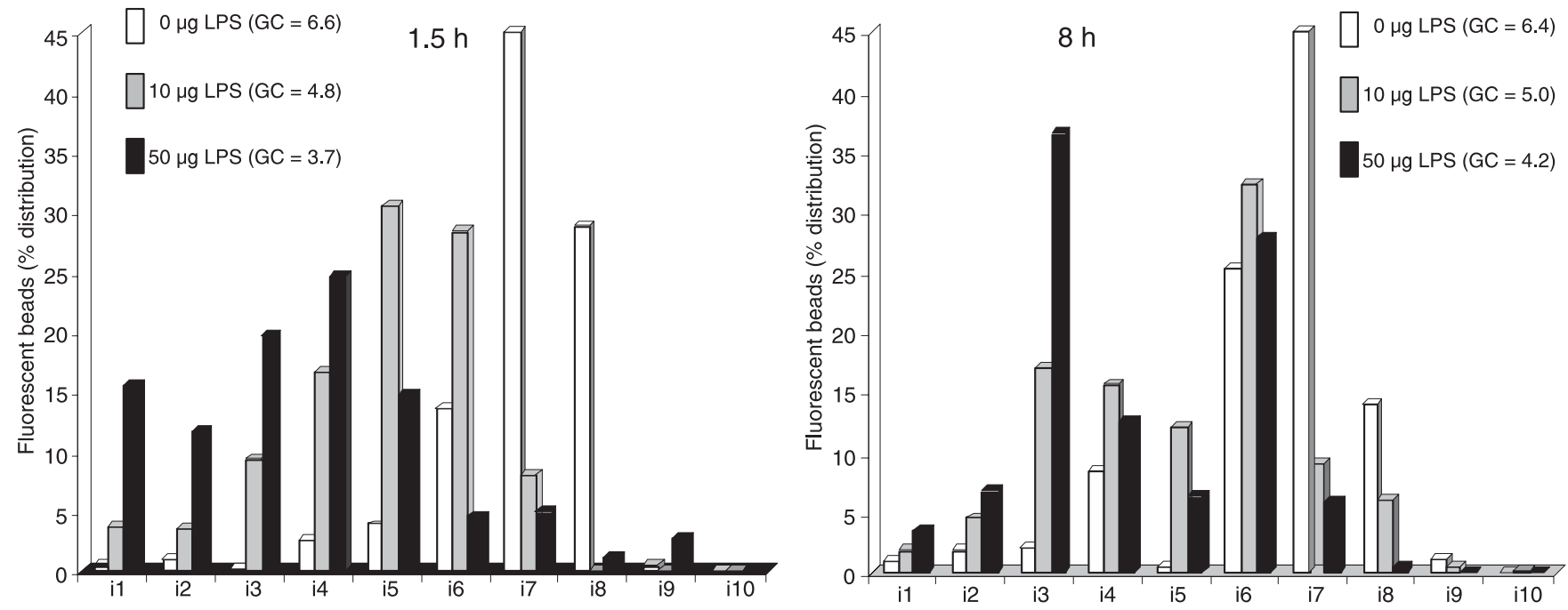

Figure 3. Effect of lipopolysaccharide (LPS) on gastric emptying and gastrointestinal transit. $A$, Gastric retention and geometric center (GC) at $1.5 \mathrm{~h}$ and $8 \mathrm{~h}$ after LPS injection. (GC indicates how far the center of gravity of the distribution of the microbeads reached beyond the pylorus into the small intestine. GC of $1=$ minimum transit; $\mathrm{GC}$ of $10=$ maximum transit). Results are reported as means $\pm \mathrm{SEM}$ for $7-8$ animals in each group. ${ }^{*}<<0.05$ vs control (one-way analysis of variance and Bonferroni $t$-test). $B$, Transit histograms. The $y$-axis indicates the amount of fluorescent beads within each segment as a percentage of the total amount of beads in the intestinal tract. Means are shown for 7-8 animals in each group. The x-axis represents small intestinal segments i1 to i10. 
trointestinal transit in otherwise untreated mice (\%GR: $18.0 \pm 2.5$ with saline vs $12.8 \pm$ $0.9 \%$ with anti-TNF- $\alpha$, GC: $6.4 \pm 0.1$ with saline vs $6.7 \pm 0.1$ with anti-TNF- $\alpha, \mathrm{N}=5$ for each group, $\mathrm{P}>0.05$ ).

\section{Discussion}

The main new findings of the present study are that the LPS-induced delay in gastric emptying in early endotoxemia $(1.5 \mathrm{~h}$ after LPS administration) was associated with iNOS but not TNF- $\alpha$, whereas in late endotoxemia ( $8 \mathrm{~h}$ after LPS administration) the delay was caused by both iNOS and TNF- $\alpha$. These findings indicate that the role of TNF$\alpha$ in gastric emptying differs depending on the time after LPS administration, whereas NO appears to contribute to the delay in gastric emptying at both times.

Although iNOS inhibition significantly reversed the increase in gastric retention in early endotoxemia, consistent with the results of previous studies $(2,6)$, the reversal was incomplete. The level of iNOS mRNA in the gastrointestinal tract, which is already detectable in the absence of LPS, increases upon LPS stimulation, peaking at $3 \mathrm{~h}$ after ip LPS administration in rats (19). Thus, the activity of iNOS may not yet be fully realized $1.5 \mathrm{~h}$ after LPS administration. Therefore, in addition to iNOS, other mechanisms may be involved in the delay in gastric emptying during early endotoxemia. Molecules such as cyclooxygenase-2 may play a role, as also reported by others $(20,21)$. During late endotoxemia, iNOS inhibition also reversed, almost completely, the increase in gastric retention. This finding is consistent with a previous study in rats, in which iNOS inhibition with aminoguanidine (a selective iNOS inhibitor) administered $5 \mathrm{~h}$ after LPS administration partially reversed the delay in gastric emptying in late endotoxemia (2).

What is most intriguing is that in late endotoxemia TNF- $\alpha$ neutralization also reversed the increase in gastric retention. The remarkable difference in gastric retention between the values observed at $1.5 \mathrm{~h}$ and those observed at $8 \mathrm{~h}$ may suggest that the mechanisms of dysmotility are different. The

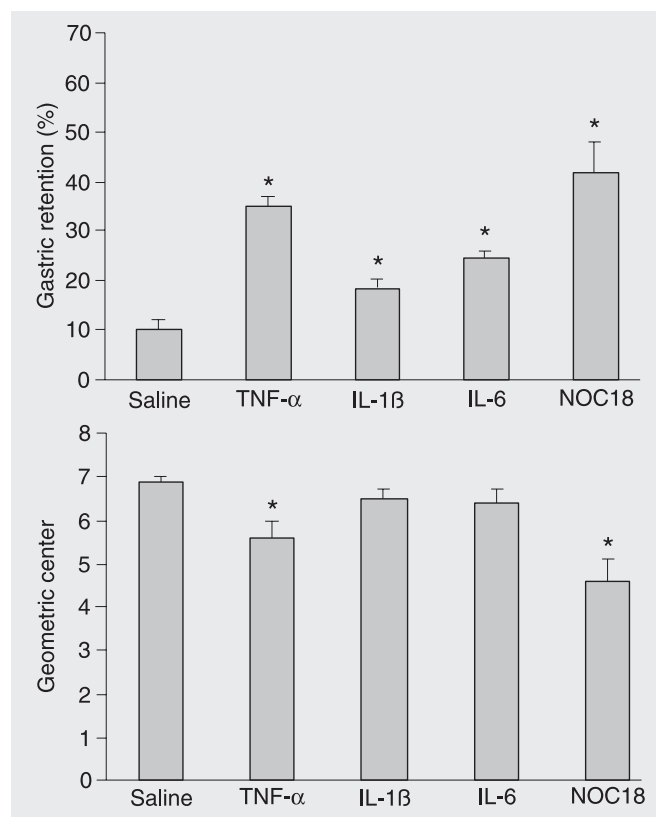

Figure 4. Effect on gastric retention and gastrointestinal transit of $2 \mu \mathrm{g}$ ip tumor necrosis factor$\alpha($ TNF- $\alpha)$, interleukin- $1 \beta$ (IL-1ß), and IL-6, and $300 \mu \mathrm{g}$ sc 1 -hydroxy-2-oxo-3,3-bis (2-aminoethyl)-1-triazene (NOC18, an NO donor). Gastric retention and geometric center were measured $30 \mathrm{~min}$ after saline or cytokine, or $1 \mathrm{~h}$ after NOC18 administration. Data are reported as means \pm SEM for 7-9 animals in each group. ${ }^{*} \mathrm{P}<0.05$ vs saline (one-way analysis of variance and Bonferroni $t$-test).
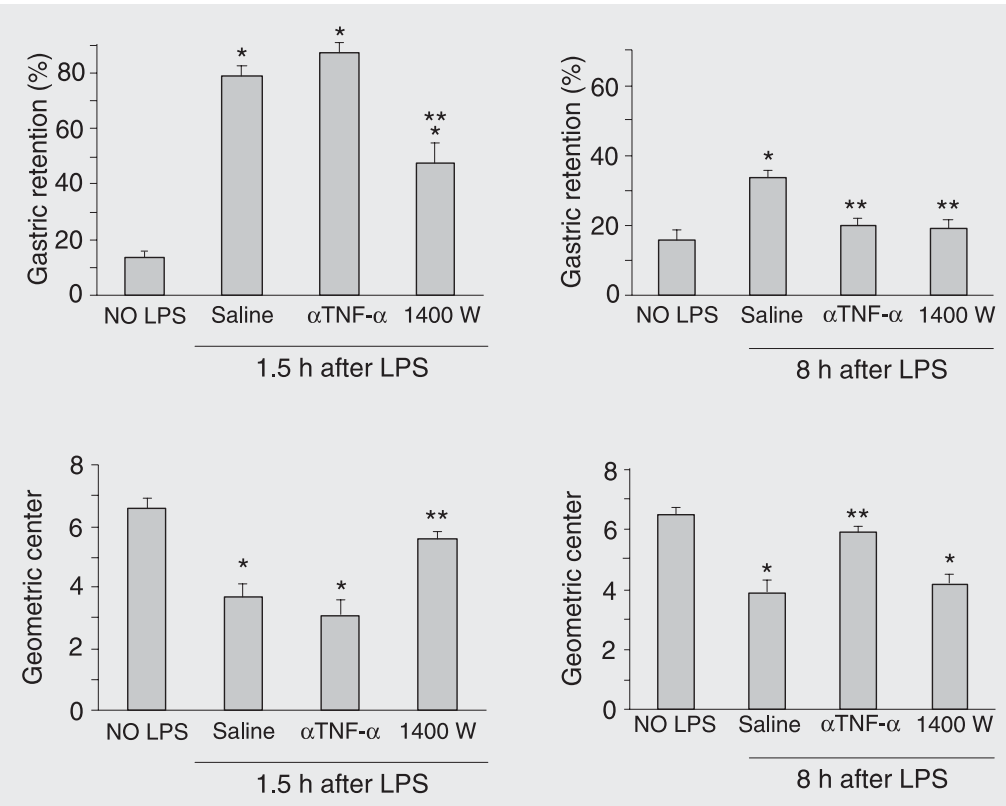

Figure 5. Effect of saline (ip), N-(3-(aminomethyl) benzyl) acetamidine (1400 W, a selective inducible nitric oxide (NO) synthase inhibitor, $150 \mu \mathrm{g}$, ip), and an antibody to tumor necrosis factor- $\alpha(\alpha$ TNF- $\alpha, 200 \mu \mathrm{g}$, ip) during early (1.5 h after $50 \mu \mathrm{g}$ ip lipopolysaccharide, LPS) and late (8 $\mathrm{h}$ after LPS administration) endotoxemia. Data are reported as means \pm SEM for 9-11 animals in each group. ${ }^{*} \mathrm{P}<0.01$ vs NO LPS; ${ }^{*} \mathrm{P}<0.01$ vs saline (one-way analysis of variance and Bonferroni $t$-test). 
reason for the successful reversal with both TNF- $\alpha$ neutralization and iNOS inhibition in late endotoxemia is not known but it may be that both TNF- $\alpha$ and iNOS contribute independently to the delay in gastric emptying. We assume that the effect of these two substances on the delay in gastric emptying is more than additive; thus the inhibition of either one can dramatically improve the delay. Another possible reason may be that TNF- $\alpha$ delays the gastric emptying via iNOS activation, as TNF- $\alpha$ has been shown to stimulate NOS activity (13).

There has been only one report describing the effect of NO and TNF- $\alpha$ on intestinal transit during endotoxemia (5). The study suggested that the LPS-induced disturbances in gastrointestinal transit during early endotoxemia ( $1.5 \mathrm{~h}$ after LPS administration) are not induced by TNF- $\alpha$ (but most likely by $\mathrm{NO}$ ), while in late endotoxemia ( $8 \mathrm{~h}$ after LPS administration) the delay in intestinal transit is induced by TNF- $\alpha$. In the same study, lactoferrin was administered orally to endotoxemic mice in order to indirectly deplete TNF- $\alpha$. The lactoferrin treatment effectively reversed the LPS-induced delay in intestinal transit (5); however, since the depletion of TNF- $\alpha$ was indirect, the possibility of other effects of lactoferrin (such as the depletion of IL-6) could not be ruled out. In the present study, we directly neutralized TNF- $\alpha$ using an antibody, thus clearly demonstrating that TNF- $\alpha$ is a primary cytokine that delays gastrointestinal transit during late endotoxemia.

In our study, treatment with $1400 \mathrm{~W}$ had no effect on the LPS-induced delay of gastrointestinal transit in late endotoxemia. However, in a previous study in which $1400 \mathrm{~W}$ was given before LPS and gastrointestinal transit was measured $18 \mathrm{~h}$ later (6), the delay in gastrointestinal transit was reversed. One possible explanation for these findings is that the improved transit observed in the previous study was due to attenuated endotoxemia because the general well-being of the mice was also significantly improved (6).

Other research has shown that LPS-induced TNF- $\alpha$ production occurs in the early phase of sepsis and that serum as well as intestinal levels of TNF- $\alpha$ decrease in the later phase $(5,22)$. It is therefore unclear why TNF- $\alpha$ contributed significantly to both the delay in gastric emptying and gastrointestinal transit in late endotoxemia (when TNF- $\alpha$ concentrations are low) but not the delay in early endotoxemia (when TNF- $\alpha$ concentrations are high). This issue was addressed in a previous study investigating the role of TNF$\alpha$ in LPS-induced delay in gastrointestinal transit, without clear answers (5). We found that TNF- $\alpha$ per se delayed gastric emptying and gastrointestinal transit. Our study suggests that the TNF- $\alpha$ surge in the early phase of sepsis may be unrelated to the delay in gastrointestinal motility in late endotoxemia, because TNF- $\alpha$ neutralization was performed just before the 8-h measurement. One possible explanation is that the sensitivity of the TNF receptor to TNF- $\alpha$ may be altered in the cytokine/humoral milieu of endotoxemia.

The effect of LPS on intestinal transit is still controversial $(1,5-7)$. We found that gastrointestinal transit was delayed by LPS, which is consistent with the reported "ileus" with endotoxemia (5-7), but some studies have shown accelerated transit during endotoxemia $(1,5)$. There are several possible explanations for this discrepancy. These include differences in the doses of LPS used, the types of LPS used, and the timing of LPS administration. We suggest that differences in measurement methods could also account for the discrepancy. There are two ways of assessing gastrointestinal transit: measuring the position of the leading edge of the marker or measuring the distribution of the marker within the gastrointestinal tract (such as the geometric center). In endotoxemia, especially in the early phase, massive amounts of fluid may accumulate in the intestinal tract. 
This fluid may easily be displaced distally when the gastrointestinal tract is removed in preparation for the measurement. We believe that the distal displacement of markers may severely affect the results with the leading edge method, but minimally affect the results with the geometric center method (which we employed), because the latter measures the center of gravity of the marker along the intestinal tract. As shown in the transit histogram (Figure 3B), at $1.5 \mathrm{~h}$ after treatment with $50 \mu \mathrm{g}$ LPS (when the gastrointestinal tract becomes severely edematous and contains an excessive amount of fluid within the lumen) the leading edge of the beads progressed more distally, while the geometric center was positioned more proximally than in the absence of LPS treatment. The discrepancy between the position of the leading edge and the geometric center may result in an accelerated measurement when intestinal transit is assessed using the leading edge method. We did not observe such a discrepancy at $8 \mathrm{~h}$, when edema of the tract and fluid accumulation in the lumen were considerably relieved. However, as we did not design the protocol to specifically study this issue and we were very careful to minimize the distal displacement of accumulated fluid containing the fluorescent marker during preparation of the intestine, further studies will be needed to test this hypothesis.

The mechanisms underlying LPS inhibition of gastrointestinal motility are complex. It appears that, $i N O S$ and TNF- $\alpha$ contribute to the inhibition, and the extent of their participation differs at different times after LPS administration. iNOS contributed to the disturbances in gastrointestinal motility in early and late endotoxemia, while TNF- $\alpha$ primarily contributed to the disturbances in late endotoxemia. However, sepsis in clinical settings is far more complicated than in this animal model which utilizes the administration of LPS (23). Although we believe that our findings provide important insights into the mechanism of sepsis-induced gastrointestinal motility disturbances, great care should be taken when attempting to extrapolate our results to sepsis-induced gastrointestinal complications in patients.

\section{References}

1. Wirthlin DJ, Cullen JJ, Spates ST, Conklin JL, Murray J, Caropreso DK, et al. Gastrointestinal transit during endotoxemia: the role of nitric oxide. J Surg Res 1996; 60: 307-311.

2. Takakura K, Hasegawa K, Goto Y, Muramatsu I. Nitric oxide produced by inducible nitric oxide synthase delays gastric emptying in lipopolysaccharide-treated rats. Anesthesiology 1997; 87: 652-657.

3. Collares EF. Effect of bacterial lipopolysaccharide on gastric emptying of liquids in rats. Braz J Med Biol Res 1997; 30: 207-211.

4. Calatayud S, Barrachina MD, Garcia-Zaragoza E, Quintana E, Esplugues JV. Endotoxin inhibits gastric emptying in rats via a capsaicin-sensitive afferent pathway. Naunyn Schmiedebergs Arch Pharmacol 2001; 363: 276-280.

5. Ceregrzyn M, Kamata T, Yajima T, Kuwahara A. Biphasic alterations in gastrointestinal transit following endotoxaemia in mice. Neurogastroenterol Motil 2001; 13: 605-613.

6. de Winter BY, Bredenoord AJ, de Man JG, Moreels TG, Herman AG, Pelckmans PA. Effect of inhibition of inducible nitric oxide synthase and guanylyl cyclase on endotoxin-induced delay in gastric emptying and intestinal transit in mice. Shock 2002; 18: 125-131.

7. Overhaus M, Togel S, Pezzone MA, Bauer AJ. Mechanisms of polymicrobial sepsis-induced ileus. Am J Physiol Gastrointest Liver Physiol 2004; 287: G685-G694.
8. Guerrero-Lindner E, Castro M, Munoz JM, Arruebo MP, Murillo MD, Bueno L, et al. Central tumour necrosis factor-alpha mediates the early gastrointestinal motor disturbances induced by lipopolysaccharide in sheep. Neurogastroenterol Motil 2003; 15: 307-316.

9. Inada T, Asai T, Yamada M, Shingu K. A new method using flow cytometry to measure the effects of drugs on gastric emptying and gastrointestinal transit in mice. Arzneimittelforschung 2004; 54: 557562.

10. Inada T, Asai T, Yamada M, Shingu K. Propofol and midazolam inhibit gastric emptying and gastrointestinal transit in mice. Anesth Analg 2004; 99: 1102-1106.

11. Osinski MA, Seifert TR, Cox BF, Gintant GA. An improved method of evaluation of drug-evoked changes in gastric emptying in mice. $J$ Pharmacol Toxicol Methods 2002; 47: 115-120.

12. Shibuta S, Mashimo T, Ohara A, Zhang PZ, Yoshiya I. Intracerebroventricular administration of a nitric oxide-releasing compound, NOC18, produces thermal hyperalgesia in rats. Neurosci Lett 1995; 187: 103-106.

13. Lodato RF, Khan AR, Zembowicz MJ, Weisbrodt NW, Pressley TA, $\mathrm{Li}$ YF, et al. Roles of IL-1 and TNF in the decreased ileal muscle contractility induced by lipopolysaccharide. Am J Physiol 1999; 276: G1356-G1362. 
14. Coimbra CR, Plourde V. Abdominal surgery-induced inhibition of gastric emptying is mediated in part by interleukin-1 beta. $A m \mathrm{~J}$ Physiol 1996; 270: R556-R560.

15. Endo Y, Kumagai K. Induction by interleukin-1, tumor necrosis factor and lipopolysaccharides of histidine decarboxylase in the stomach and prolonged accumulation of gastric acid. $\mathrm{Br} J$ Pharmacol 1998; 125: 842-848.

16. Marini M, Bamias G, Rivera-Nieves J, Moskaluk CA, Hoang SB, Ross WG, et al. TNF-alpha neutralization ameliorates the severity of murine Crohn's-like ileitis by abrogation of intestinal epithelial cell apoptosis. Proc Natl Acad Sci U S A 2003; 100: 8366-8371.

17. Calatayud S, Garcia-Zaragoza E, Hernandez C, Quintana E, Felipo $\mathrm{V}$, Esplugues JV, et al. Downregulation of nNOS and synthesis of PGs associated with endotoxin-induced delay in gastric emptying. Am J Physiol Gastrointest Liver Physiol 2002; 283: G1360-G1367.

18. Suliburk JW, Helmer KS, Kennison SD, Mercer DW, Robinson EK. Time-dependent aggravation or attenuation of lipopolysaccharide- induced gastric injury by nitric oxide synthase inhibition. J Surg Res 2005; 129: 265-271.

19. Eskandari MK, Kalff JC, Billiar TR, Lee KK, Bauer AJ. LPS-induced muscularis macrophage nitric oxide suppresses rat jejunal circular muscle activity. Am J Physiol 1999; 277: G478-G486.

20. Sanders $\mathrm{KM}$. Role of prostaglandins in regulating gastric motility. Am J Physiol 1984; 247: G117-G126.

21. Stein J, Zeuzem S, Uphoff K, Laube H. Effects of prostaglandins and indomethacin on gastric emptying in the rat. Prostaglandins 1994; 47: 31-40.

22. Glatzle J, Leutenegger CM, Mueller MH, Kreis ME, Raybould HE, Zittel TT. Mesenteric lymph collected during peritonitis or sepsis potently inhibits gastric motility in rats. J Gastrointest Surg 2004; 8: 645-652.

23. Buras JA, Holzmann B, Sitkovsky M. Animal models of sepsis: setting the stage. Nat Rev Drug Discov 2005; 4: 854-865. 